\title{
SUPRI HEAVY OIL RESEARCH PROGRAM
}

FINAL REPORT

FEBRUARY 22, 1990 - MARCH 21, 1993

William E. Brigham, Principal Investigator Henry J. Ramey Jr., Principal Investigator Louis M. Castanier, Technical Manager

Stanford University Petroleum Research Institute Stanford, California 94305

Prepared for the U.S. Department of Energy Under Contract No. DE-FG22-90BC14600

Thomas B. Reid, Technical Project Officer Project Manager

EOR Processes

P.O. Box 1398

Bartlesville, Oklahoma 74005

UNITED STATES DEPARTMENT OF EPJERGY 


\section{TABLE OF CONTENTS}

$\underline{\text { Page }}$

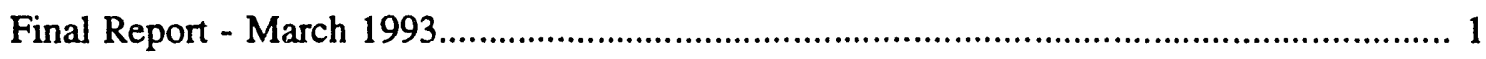

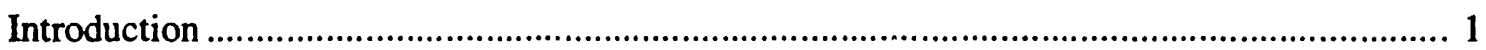

Stanford University Petroleum Research Institute SUPRI ............................................ 3

SUPRI Results

Project 1. Flow Properties Studies............................................................................. 5

Project 2. In-situ Combustion ................................................................................... 6

Project 3. Additives to Improve Mobility Control...................................................... 8

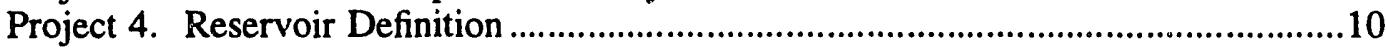

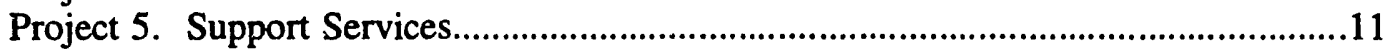

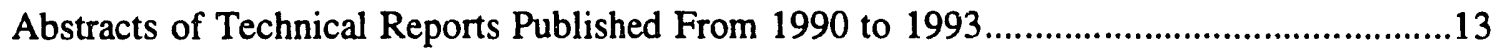

SUPRI TR 70

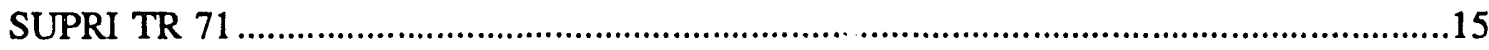

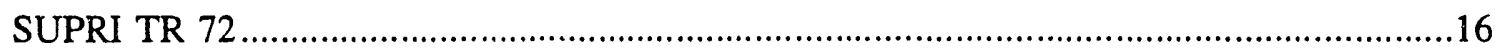

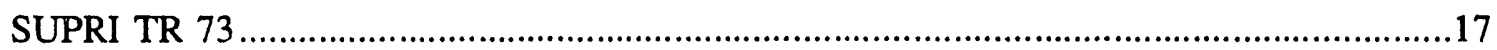

SUPRI TR 74

SUPRI TR 75

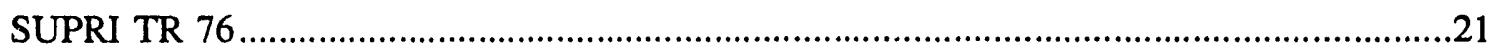

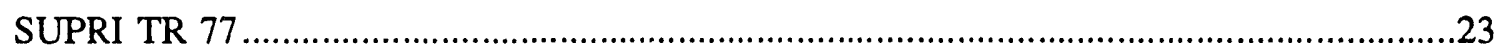

SUPRI TR 78

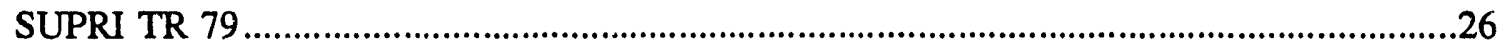

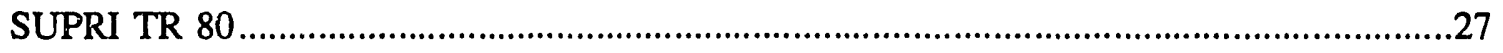

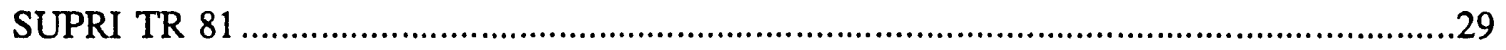

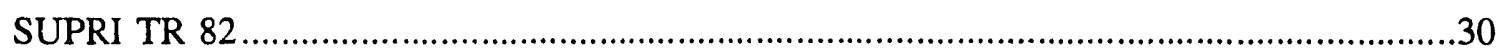

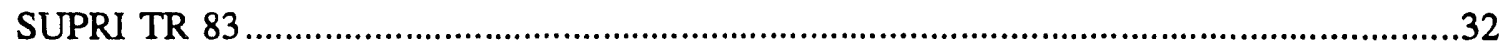

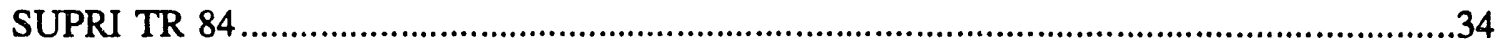

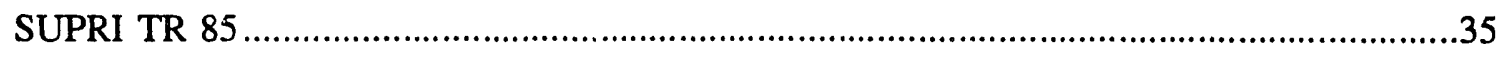

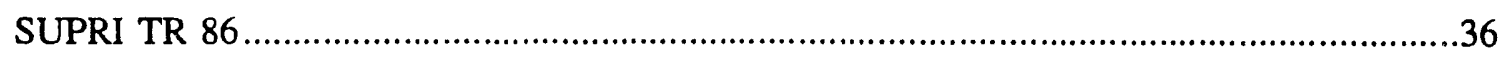

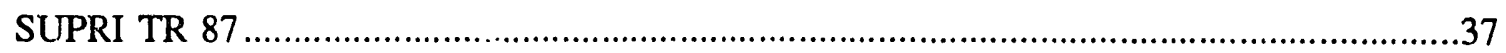


SUPRI TR 88

SUPRI TR 89

SUPRI TR 90

SUPRI-A Publications Since 1989.

DISCLAIMER

This report was prepared as an account of work sponsored by an agency of the United States Government. Neither the United States Government nor any agency thereof, nor any of their employees, makes any warranty, express or implied, or assumes any legal liability or responsibility for the accuracy, completeness, or usefulness of any information, apparatus, product, or process disclosed, or represents that its use would not infringe privately owned rights. Reference herein to any specific commercial product, process, or service by trade name, trademark, manufacturer, or otherwise does not necessarily constitute or imply its endorsement, recommendation, or favoring by the United States Government or any agency thereof. The views and opinions of authors expressed herein do not necessarily state or reflect those of the United States Government or any agency thereof. 


\section{Final Report}

\section{March 1993}

This report summarizes the progress of the research performed by the Stanford University Petroleum Research Institute, SUPRI, during the past three years. As three annual reports and several topical technical reports have been published by the Department of Energy during the period of performance, and technical papers have also been presented as part of our mission to transfer information, this report will be a relatively brief summary. The reader interested in more details will find a list of references at the end. These contain more detailled technical information on the projects.

\section{Introduction}

Heavy oil resources in the lower 48 states are in excess of 45 billion barrels, and estimates in Alaska, are at least 40 billion barrels. Heavy oil reserves are a large fraction of the total reserves in the United States. Canada and Venezuela also have large reserves of heavy oil. Currently, heavy oil production in the lower 48 states is about 1 million barrels per day with over half coming from thermal enhanced oil recovery processes, most in California. This production is operated by major oil companies such as Mobil, Texaco, Chevron, Shell and Unocal, or by large independents such as Santa Fe Energy. In the past five years, the oil companies involved in heavy oil production have changed their research and development programs toward short term, direct field operation support. They are contributing some funding to universities for research on medium and longer term processes. SUPRI's mission is to conduct some of this research.

In heavy oil reservoirs, primary and waterflood production of ten leave over $90 \%$ of the oil in the ground; consequently, these reservoirs constitute an attractive target for enhanced oil recovery. Different techniques have been proposed to enhance oil recovery, 
however, for heavy oils thermal recovery is the most useful. A study performed by the National Petroleum Council (1984) clearly shows that thermal recovery processes already contribute nearly $80 \%$ of all enhanced oil recovery production in the United States. Its potential for further increases is also high. It is estimated to be between 4.2 and 12 billion barrels.

The steam drive (steam flooding) process is by far the most commonly used on a commercial brsis in the United States (National Petroleum Council (1984)); most of this production is in California.

In steam drive, steam is continuously injected to displace the oil. As a result, heat is transferred to the oil-bearing formation, to the reservoir fluids, and to the adjacent cap and base rock. Thus, some of the steam condenses, which yields a mixture of steam and hot water flowing through the reservoir. The composition of this mixture will depend on many variables, such as distance, reservoir thickness, porosity, injection rate, and quality of the injected steam. The steam drive forms an oil bank ahead of the steamed zone. Recovery is also increased due to the high temperature which lowers the oil viscosity. Displacement of oil by steam flooding is controlled by factors such as well spacing, reservoir heterogeneity, formation dip, nature of the reservoir, nature of the crude oil, gravity segregation, reservoir pressure and temperature, relative permeability, mobility ratio and fluid saturations in the formation being flooded. These factors all affect the overall recovery efficiency. Research in all these areas is consequently necessary to understand and optimize the process.

One of the problems encountered in steam flooding is that the steam is lighter and less viscous than the oil. Thus steam tends to follow high permeability paths, or to flow towards the top of the reservoir. Thus some of the oil is untouched. Mobility control can help reduce these effects.

In-situ combustion, as its name indicates, burns part of the oil in-situ in order to produce the rest. In this process air is injected to supply the oxidant and driving fluid, and 
the oil is ignited at the injection well. A burning front propagates across the reservoir toward the production wells. The combustion produces heat which is transferied ahead of the front by the hot gases and steam resulting from the combustion. An oil bank is formed and produced, but gravity effects are usually important. In addition, as in steam injection, the oil mobility is improved by the heat, thus the recovery is increased. In-situ combustion is attractive because its energy efficiency is better than that of steam injection. Another point of interest is that the portion of the oil which is burned is the heaviest, and hence the less attractive for refiners.

The controlling factors for in-situ combustion are well-spacing, nature of the reservoir and the crude oil, formation thickness and dip, amount and nature of the fuel, the reaction rates, heterogeneities, reservoir pressure and temperature, oil saturation, porosity, relative permeabilities, air injection rate, and pressure.

The results of field projects using in-situ combustion have been mixed. Some very successful field operations are known as well as notable failures. This shows the need for a better understanding of all the above factors in the in-situ combustion process, and hence the need for research in this area.

In any enhanced oil recovery project it is necessary to have a good knowledge of the properties of the reservoir before initiating a process. Such techniques as well testing and well-to-well tracer flow provide useful information on the physical properties of the rock and fluids of the reservoir and the heterogeneity of the oil bearing layers. These parameters are important for understanding the overall efficiency of any oil recovery technique, and for engineering to optimize oil recovery.

\section{Stanford University Petroleum Research Institute (SUPRI)}

SUPRI (Stanford University Petroleum Research Institute) was started in 1976 to carry out a broad spectrum of heavy oil petroleum research in five main areas: (1) flow properties studies, (2) in-situ combustion, (3) additives to improve mobility control, (4) 
reservoir definition, and (5) support services. Besides the Department of Energy, there are nine oil producing companies advising on the details of the research and contributing funding. SUPRI research is near term, mid term and long term. Over 90 technical reports and over 140 technical papers have been published by SUPRI.

Results on the effect of high temperature and pressure on flow behavior, development of X-ray Cat-scanning as a core characterization method, and studies of relative permeabilities are valuable to the oil industry because these basic studies of flow properties are seldom performed in the industry laboratories because of lack of funds and personnel.

SUPRI is the only U.S. university program actively working on in-situ combustion. In-situ combustion requires less energy and causes less environmental problems than steam injection. It can contribute a significant increase to the recoverable reserves, for in-situ combustion can be used in deeper and thinner reservours than can steam injection. Only a few companies are currently active in combustion research. However, a workshop organized by SUPRI in Tulsa, Oklahoma, April 20-21, 1992 at the Department of Energy request, attracted 52 engineers from eight different countries. There was interest in the combustion process, not only from the major companies, but also from independents and research centers.

SUPRI has been a major contributor to information on the use of foaming additives to improve steam injection. SUPRI laboratory results were applied in a successful field test, and have directly contributed to the success of steam-foam in several field projects. The foam flow mechanisms are particularly important and are a difficult long term problem. Foam flow mechanisms must be understood before field projects can be properly modeled. On the shorter term, much remains to be found on optimization of foam application, and on analysis of existing or past field projects.

Formation evaluation via well testing and tracer tests requires more study. Some SUPRI results on thermal recovery well tests and well to well tracers are already being 
used by industry to better understand the reservoirs before, during, and after field projects. Understanding the nature of flow in reservoirs is crucial not only for heavy oils but for any enhanced oil recovery project. Any field pilot test should be fully monitored; the data analysis can be used for large scale expansion.

Several short term projects have been completed by SUPRI in the field support services area. These include economic evaluation and recovery process prediction, data analysis and optimization. In addition to the steam-foam pilot previously mentioned, contacts with industry and DOE are continuous. SUPRI is also involved in international work for the DOE in the U.S./Canada and U.S./Venezuela agreements. University of Southern California (USC) is funded under a subcontract to SUPRI and concentrates on steam flooding research. This research, considered near to mid term, focuses on vaporliquid flow and change of phase (heat and mass transfer), additives, and reservoir heterogeneity. USC is working on foam flow in cores, network models for vapor-liquid flow, a steam displacement visualization study, and mathematical analysis of fractured systems using fractals. This last project could be relevant to the Monterey shales and heavy oil carbonate reservoirs. USC's research complements the SUPRI work.

\section{SUPRI Results}

This section discusses some of SUPRI's past results. It is divided into the five projects representing the main research topics. Details on specific projects can be found in the reports listed in the bibliography.

\section{Project 1. Flow Properties Studies.}

Knowledge of basic flow properties such as absolute and relative permeability, wettability, and capillary pressure is needed to predict reservoir behavior during enhanced 
oil recovery processes. We must understand how various flow parameters affect results at differing operating conditions.

End effects due to capillary forces and header design can cause important errors in measuring relative permeability. A recent study (Qadeer, 1991) performed on Berea cores under a CT scanner has shown that, during unsteady state measurements, the saturation distribution in the core is crucial. Based on the data, calculations of correct relative permeability curves may require three-dimensional simulation. This work is ongoing.

Fractured reservirs are an important resource. Studies of the fluid transfer between the matrix and the fracture network have been initiated and will continue during the next period of performance. A report on the preliminary results is in the draft stage.

A project on steam injection into fractured reservoirs has been initiated. The design has been finalized for an experimental apparatus to study heat and mass transfer of steam in fractured blocks. In parallel, we have used fine grid simulations on the STARS model. This complex work is just beginning, and will continue for several years.

To allow better measurements of flow parameters, an X-ray Cat-scanner was purchased, installed and calibrated (Castanier, 1988). Saturation distributions can be measured accurately. Investigation of drainage and imbibition of Salem limestone (Mossoti and Castanier, 1989) showed these processes to be dominated by capillarity. Johns et al. (1991) measured fracture apertures in natural cores. The use of the X-ray Cat-scanner is now routine procedure at SUPRI. Software development for CT data interpretation and display is an important part of our effort. This work is ongoing and will yield a user friendly sofware package compatible with our existing equipment.

\section{Project 2. In-situ Combustion}

In-situ combustion is the most energy efficient of thermal recovery techniques. It is also better than steam from an environmental viewpoint because less pollutants are released into the atmosphere compared to an equivalent steam project. The amount of air or 
oxygen required to burn a given volume of reservoir, and the amount of oil that can be recovered, are important design parameters. Experimental modeling in a combustion tube is an excellent method to obtain an understanding of the mechanisms affecting the process.

A combustion tube was built in 1978 and it has been recently improved by upgrading the data acquisition systems. A new study concerns the effect of metallic additives on combustion. Water soluble metallic salts have been used in kinetic experiments to study the effect of catalysts on the amount and nature of the fuel formed (De los Rios, 1988). Significant changes were observed when soluble iron and tin salts were dissolved in the reservoir water. Similar results were found in tube runs (Baena, 1988; Holt et al., 1992). This work could extend the range of application of in-situ combustion to lighter oils as shown by the results of runs made with a $34^{\circ} \mathrm{API}$ California oil.

An analytical solution was derived for the flow behavior of steam, oil and water (Wingard, 1989). The model ignored the effects of heat losses to the overburden, but clearly showed the heat and fluid flow behavior both in the steam zone ahead of a combustion front, and in steam flooding. These solutions are useful because they show how reservoir fluid and thermal parameters interact to affect the displacement behavior.

Distillation is the main mechanism for fuel deposition. A general method was developed to compute steam distillation yield and to quantify oil quality changes during steam injection ( $\operatorname{Lim}$ et al., 1992). Steam distillation data from the literature were correlated with the yields obtained from DOE crude oil assays using the equivalent normal boiling point. Blending of distilled components with the initial oil results in API gravity increases which are similai to those observed in field and laboratory operations. This work is applicable to steam drive as well as combustion.

To model the reactions occurring during in-situ combustion, it is necessary is understand the kinetics of these reactions (Fassihi et al., 1980; Fassihi et al., 1984). An apparatus was designed to oxidize a small sample of oil and measure the composition of the produced gases during programmed heating. A new kinetics model has been developed 
which takes into account grain size and the fact that the fuel is a hydrocarbon, not pure carbon (Mamora, 1992). The model uses two kinetic reactions, plus it accounts for the surface area for diffusion. This model matches a broader range of results than the previous model, showing good agreement with data obtained on Cold Lake bitumen, Hamaca (Venezuela) oil and Huntington Beach crude.

\section{Project 3. Additives to Improve Mobility Control}

Our literature surveys showed that foam could be generated in-situ, and could be used to improve gas drives. As a result, a laboratory study was initiated which focused on two objectives: temperature stability of foaming agents, and foam flow properties in porous media. The first part, completed in 1987, yielded a screening protocol for surfactant additives to reduce the mobility of steam. Our efforts in the past three years have mainly focussed on studying foam flow behavior in porous media.

To serve as a mobility control agent, a foam must generate a blocking action in porous media. Several experiments were designed to investigate this effect.

At the microscopic level. air at near atmospheric pressure was injected into porous micromodels filled with an aqueous solution of surfactant, or, for comparison, with water only. Visual observations showed that the wetting phase (surfactant solution) causes a large reduction of effective air mobility, even at low surfactant concentrations. Hombrook et al. (1992) introduced residual oil into the micromodels. They found that a slug of surfactant followed by gas performed better than foam injection because of wettability changes. Hombrook et al. have also improved the micromodels by using computer aided design.

Measurements of the saturation history during foam injection into water saturated sandpacks helped in the development of a mathematical model for transient foam flow (Liu et al., 1991). The CT scanner was a valuable tool for understanding the results seen. The mathematical model is based on a combination of Buckley-Leverett type equations with a term added for mixing. The model compares well with experimental saturation distribution 
results, but this work will need to be extended to obtain a better match of the pressure data, and data under other operating conditions.

The previously-described work was performed at low pressures and temperatures with nitrogen as the gas phase of the foam. To simulate a one-dimensional steam drive, a high pressure linear model was designed to study displacements of oil and water at various saturations.

In this apparatus, Shallcross (1989) investigated the effect on the pressure gradients of the chemical structure of surfactants. He found that longer chain lengths caused higher pressure gradients. Alpha olefin sulfonates seemed to generate the strongest foams. Hamida (1990) found that coinjection of steam, nitrogen and a surfactant solution was unable to generate foam with oil present. By contrast, Hutchinson (1991) used surfactant slugs followed by steam and nitrogen, and foam was generated with oil present. He also investigated the effect of steam quality, concentration and slug size on the pressure gradients generated. Razzaq (1992) expanded Hutchinson's work to four different surfactants.

The CT imaging technique together with temperature and pressure measurements were used to follow steam propagation during stedm and steam foam injection experiments in a three-dimensional (1/4 of a 5-spot) model (Demiral et al., 1992). During the experiments, steam was injected continuously at a constant rate into the water saturated model and CT scans were taken at six different cross sections. Heat losses were measured using heat flux sensors, and temperature and pressure data were collected at three different levels in the model. CT pictures and three-dimensional temperature distributions were comparec and analyzed in each section.

During the runs where foam was present, the saturation distributions obtained from CT pictures showed a piston like displacement. However, the temperature results indicated steam override, although the override was reduced by the foam. These results show that 
pressure/temperature data alone are not sufficient to study steam foam in the presence of noncondensible gas.

The main advantage of the comprehensive data gathering approach of these various projects is to offer new insight into the mechanisms of oil displacement by steam and steam foam. Another useful application of these models is as raw data for proper calibration of thermal numerical simulators. To this end, an effort is in progress to calculate and analyse the heat losses from our five-spot model using the STARS numerical simulator. The data from the experiments are being compared to the simulator results. A report on this project is scheduled for 1994.

\section{Project 4. Reserwoir Definition}

To characterize a formation, all available information from logs, cores, pressure tests, tracer tests, numerical simulators, and geologic, and geophysical studies should be considered. Several SUPRI projects concerning formation characterization are discussed in the following.

A study of transient flow through perforations was completed in 1989 (Ahmed et al., 1989). The analytical solutions obtained from a mathematical model allow insight into the parameters required to optimize the perforating process. Further work needs to be done in this model to show how to perform these optimizations.

In projects with at least two wells, the objectives often are to define communication, reservoir heterogeneities and average properties of the tested formations. Abbaszadeh and Brigham (1983) is the most complete work to date on how to evaluate well-to-well tracer tests for reservoir layering. This study was extended to show the results expected from nonhomogeneous layers (Mishra, 1988).

An attempt was made in 1990 to expand the work to tracer tests at nonunit mobility ratios. As no analytical solution to this problem exists, we used UTCHEM, the University of Texas numerical simulator. This program has excellent numerical dispersion control 
features; however, we were unable to obtain accurate enough computations except under a few limiting cases. This work should be pursued further, for well-to-well tracer testing is an important way to evaluate reservoir heterogeneity.

Many low pressure heavy oil reservoirs, using steam or in-situ combustion, are gravity drainage systems. Results of new work on gravity drainage well testing have recently been presented (Ramey, 1988 and Ramey, et al., 1989). Finite difference modeling of transient gravity drainage flow is cnder way (Couri, 1993), along with further studies to compare these results to analytical models and to ideal gas transient flow. The work on this problem shows marked differences from classical transient testing behavior. Interim reports on this problem are in the draft stage and will be completed shortly. Further work is planned on this important problem.

\section{Project 5. Support Services}

In addition to numerous contacts with representatives of the oil industry and with other research and academic institutions, SUPRI-A is active in supporting field projects related to our research. One of our interests is economic evaluation and optimization of different thermal oil recovery methods, and another is the technical support of DOE or industry sponsored field projects.

Recently, Gadjica et al. (1990) developed a semi-analytical model for steam injection into one-dimensional linear and two-dimensional vertical cross-sectional systems. The model includes dip, compressible formation and thermal expansion, and can be used to calculate the steam zone saturation as well as water front position. Heat losses and gravity override are also included. Results from the model were successfully correlated using data from a commercial numerical simulator.

This project is being expanded to include layered reservoirs. The model takes into account heat transfer between layers separated by an impermeable boundary. The results of 
the semi analytical model have been compared to cata provided by the STARS simulator. A report on this project is expected in 1993.

Various optimization methods have been studied for well test analysis, production schedules and reservoir simulation. A report on this project was written in 1990 (Barua and Horne). Recently, a study of optimization of tubing size and surface facilities was completed by Ravindran. A report on this work is in the draft stage, and will be extended in future years.

Rates of multiphase flow have been measured using an ultrasonic flowmeter. An interim report on this project was published (Dannert and Horne (1993)). This work will be extended.

SUPRI has supported several DOE and industry research programs. In the United States, interaction with other universities (U.C. Berkeley and University of Southern California) who are working on related topics, has been continuous and mutually beneficial. Researchers from the three universities have met regularly. SUPRI personnel and personnel from the National Institute for Petroleum and Energy Research (NIPER) exchange visits to each others laboratories and information on thermal recovery techniques.

SUPRI has provided technical support to DOE international exchange progran.s with Venezuela and Canada. Meetings are held frequently between representatives of INTEVEP (Venezuela Petroleum Research Institute) and SUPRI. Discussions and meetings were also held with personnel from the Alberta Research Council (ARC), Institut Francais du Petrole (IFP), Middle East Technical University (Turkey) and the University of Calgary. Also, papers have been presented regularly at the yearly meetings of the International Energy Agency (IEA).

Visiting scholars from the U.S.A., Turkey, Nigeria, Venezuela, Mexico, France, Australia, England and the Peoples' Republic of China have worked at SUPRI. Their efforts have ranged over a spectrum of laboratory experimental, computational and analytical research in the SUPRI program. 
SUPRI personnel have participated in many national and international technical meetings. National meetings were sponsored by the Society of Petroleum Engineers, American Institute of Chemical Engineers, Geothermal Resources Council, American Chemical Society, American Geophysical Union, and American Geological Society; international technical meetings were sponsored by IEA, NATO, and Venezuelan Heavy Crude Symposia, and European EOR Symposia.

\section{Abstracts of Technical Reports Published From 1990 to 1993}

The following pages present abstracts of reports published by SUPRI during the contract period. Complete copies of these reports can be obtained from DOE or from the Stanford University Petroleum Engineering Department on request. In addition, a number of technical papers have been written on the topics discussed in here. A listing of these papers is also enclosed in the references, and copies will be sent on request. 


\title{
A STUDY ON NEWTON RELATED NONLINEAR METHODS \\ IN WELL TEST ANALYSIS, PRODUCTION SCHEDULE \\ OPTIMIZATION AND RESERVOIR SIMULATION
}

\author{
SUPRI TR 70
}

By

Jawahar Barua

Norember 1989

\begin{abstract}
This is a study on the use of alternative nonlinear methods in automated well test analysis, production and injection schedule optimization and in reservoir simulation.

In automated well test analysis the advantages and disadvantages of recond-order partial derivatives are investigated. Newton's method is shown to be prone to difficulties, however by adjusting the eigenvalues of the Hessian matrix, the performance can be substantially improved.

In optimizing the cyclic steam injection process, Newton's method is compared with the Quasi-Newton method using a simplified model to simulate the process. The Quasi-Newton method does significantly better than Newton's method in saving function evaluations. Specific operating strategies for the process are identified: the need to eliminate soak, the need for greatly increased steam volumes and temperatures, and the need to optimize a combination of economic objectives.

The two methods are then compared in reservoir simulation. Tests show that while it is possible to use the Quasi-Newton method to build up inverse Jacobians as the iterations proceed, for difficult problems the method requires the use of matrix solution techniques. The method then becomes directly comparable to Newton's method. Tests show that depending upon the linear scheme used, and the difficulty of the problem, the Quasi-Newton method may prove to be less expensive than Newton's method in certain cases.

The study also addresses the issue of building scalable parallel reservoir simulators. Residual constraints are used to improve the robustness of ise parallel matrix solution scheme. The solution of the constraint matrix is shown to be a critical point in achieving good performance on a parallel machine.
\end{abstract}




\title{
MULTICOMPONENT, MULTIPHASE FLOW IN POROUS MEDIA WITH TEMPERATURE VARIATION
}

\author{
SUPRI TR 71
}

By

J.S. Wingard and F.M. Or, Jr.

\author{
December 1989
}

\begin{abstract}
Recovery of hydrocarbons from porous medix is an ongoing concem. Advanced rechniques augment conventional recovery methods by injecting fluids that favorably interact with the oil. These fluids interact with the oilby energy transfer, in the case of steam injection, or by mass transfer, as in a miscible gas flood. Often both thermal and compositional considerations are important. An understanding of these injection methods requires knowledge of how temperature variations, phase equilibrium and multiphase flow in porous media interact

The material balance for each component and energy balance are cast as a system of non-strictly hyperbolic partial differential equations. This system of equations is solved using the method of characteristics. The model takes into account the phase behavior by using the Peng-Robinson equation of state to partition the individual components into different phases. Temperature effects are accounted for by the energy balance. Flow effects are modelled by using fractional flow curves and a Stone's three phase relative permeability model.

Thues major problems are studied in this dissertation. Exch new problem adds an level of interaction to the solution before. The first problem eliminates the phase behavior aspect of the problem by studying the flow of a single component as it undergoes an isothermal phase change. The second problem couples the effects of temperature and flow behavior by including a second component that is immiscible with the original ccmponent. Finally, phase behavior is added by using a set of three partially miscible components that partition into two or three separate phases.

Solutions for these equations are formed by apreading waves that propagate in space and time with a constant velocity. The spreading wave regions are connected by jump discontinuities or zones of constant state. The solutions are presented for the three example sysiems in the form of saturation or composition profiles and solution paths in the composition space. An analysis of the effect of verying some of the important parameters are also presented for each displacement system.
\end{abstract}




\title{
A COMPARISON OF RELATIVE PERMEABILITY FROM CENTRIFUGING VERSUS COREFLOODING
}

\author{
SUPRI TR 72
}

By

David T. Shimbo

February 1990

\begin{abstract}
Relative permeability and capillary pressure data from both centrifuge and coreflooding experiments on the same Berea sandstone will be analyzed using both analytical and simulation techniques. A linear two phase simulation model of fluid displacement from a core will be built. Capillary, gravity, and viscous effects will be included.
\end{abstract}




\title{
CHARACTERIZATION OF STEAM FOAM SURFACTANTS THROUGH ONE-DIMENSIONAL SANDPACK EXPERIMENTS
}

\author{
SUPRI TR 73
}

By

D.C. Shalleross, L.M. Castanier, and W.E. Brigham

March 1, 1990

\begin{abstract}
The efficiency of a steamflood may be increased by the use of surfactants that spontaneously generate steam foam when injected into an oil reservoir. Ideally the foam preferentally forms in high permeability streaks and oil depleted regions of the reservoir through which the steam would otherwise channel. The foam diverts the steam through regions previously unconracted by the injected steam. This report describes an experimental programe conducted to study the foam-forming characteristics of $:$ range of different surfactants. Both commericially-available, and experimental surfactans were tested in a one-dimensional sandpack under controlled conditions of pressures and temperabures similar to those encountered in California oil fields. Steam and nitrogea were continuously injected into the sandpack which contained neither clay nor oil. The surfactant solutions were injected in discrete slugs of a finite duration allowing transient phenomena such as the persistence of the foam to be stu. died.

Under the conditions of the experiment, lons chain alpha olefin sulphosate surfactants were found to generate the strongest foums. Internal olefin sulphonates, linear toluene sulphomates and linear xylene sulphonate rurfactants genernted just as strong foams but only at successively higher concentrations. It was found that the strength of the foam produced by a surfactant of a parcicular chemical structure ircreased with increasing alkyl chain length.

The novel use of heat flux senson attached to the outride of the candpeck allowed a better understanding of the heat transfer mechanisms opernting within the aystem. Such an understanding is necessary if the experimental observations are to interpreted correctly.
\end{abstract}




\title{
THE ACCURA'TE MEASUREMENT OF HEAT FLUX USING THIN FUL HEAT FLUX SENSORS WITH APPLICATION TO PETROLEUM ENGINEERING
}

\author{
SUPRI TR 74
}

By

D.C. Shallecoss and D.G. Wood

June 1990

\begin{abstract}
A thorough understanding of the thermal processes occurring within an experimental system is usually vital in correctly interpreting experimental observations, yet most researchers rely solely on temperanure-measuring devices such as thermocouples to study these thermal processes. Heat flux is a process variable that is rarely, yet readily measured. This report details how commercially-available thin film heat flux sensors may be used within the petroleum engineering laboratory to accurately measure heat flux.

As with many other devices, the presence of a heat flux sensor often changes the magniwde of the quantity to be measured. The application of a sensor to a surface will disturb the flow of heat through the surface. Heat flow will be disturbed because the sensor possesses a non-zero thermal resistance, the contact between the sensor and the surface is imperfect, and the emissivity of the sensor may differ significantly from that of the surface upon which it is placed. It is possible to correct the measured heat flux for these three potentially-significant factors to obtain the true undisturbed heat flux. In this report the data reduction equations required to perform the corrections are derived for two different experimental systems.

To illustrate the proper application of the sensor and the correct interpretation of the experimental results, a laborarory investigation is described. Five thin film heat flux sensors were used to study heat transfer processes occurring within a one-dimensional sandpack which was first steam flooded, then injected with a surfactant solution and a non-condensible gas to spontaneously generate steam foam. The sensors were attached to the outside of the sandpack beneath a layer of insulation. Their use allowed parameters such as the steam front velocity and inclination, and the quality of the produced steam to be determined. Variations in the rates of heat transfer from the sandpack to the surroundings proved to be significant with both time and position along the one-dimensional model. The sensors proved to be valuable tools in understanding the heat transfer mechanisms occurring within the system and correctly interpreting the experimental results.
\end{abstract}




\section{A SEMIANALYTICAL THERMAL MODEL \\ FOR LINEAR STEAM DRIVE}

\section{SUPRI TR 75}

By

R.J. Gajdica, W.E. Brigham, and K. Aziz

March 1990

\section{Abstract}

Thermal recovery by steam injection has proven to be an effective means of recovering heavy oil. Forecasts of reservoir response to the applicalion of stcam are necessary befcre starting a steam drive project. Thermal numerical models are available to provide forecasts. However, these models are expensive and consume a great dral of computer time. An alternative to mumerical modeling is to use an antilytiral model. Analytical models are fast, but the assumptions necessary to generate the solutions may lead to poor results. Comnon assumptions in analytiral modnls are: (1) a horizontal reservoir, (2) incompressible oil, water, and formation, and (3) no thermal expansion of the oil, water, and formation. Furthermore, many analyical models require steam zone saluration as inpul, or do not consider the water fromt when calculating production rates. Finally, one-dimensional analytical models do not consider gravity override of stcam.

A semianalytical model (SAM) lias been developed for one-dimensional lincin systems and two-dimensional linear cross-sectional systenns. Wells are locuted at hoth ends of the reservoir. At the injertion well, wet steam is injerted at a constant ratc andil cuthalpy: The production well produces at a constant flowing boltomliole pressure. The SAM includes formation dip, compressible formation, wat.cr, and oil. and therrmill

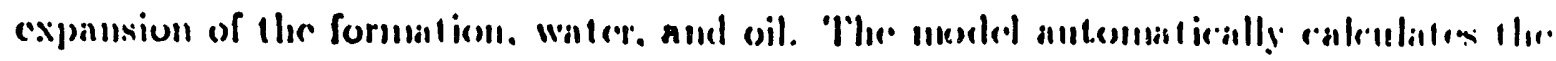

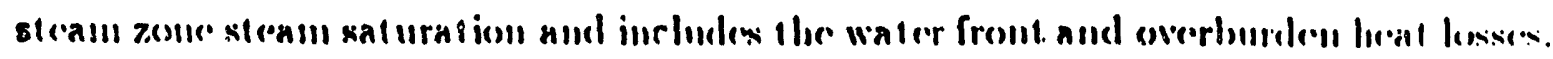

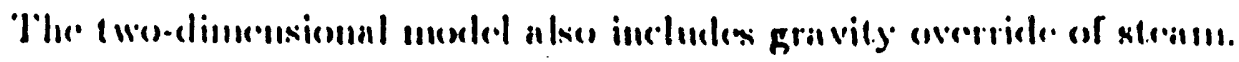


The s!estent of equatious is solverl by iterating on the injertion wedl pressure. liur

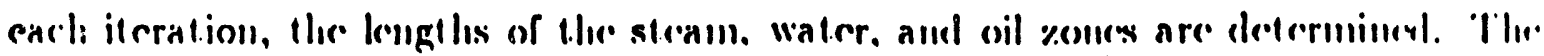

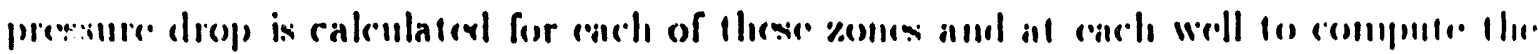

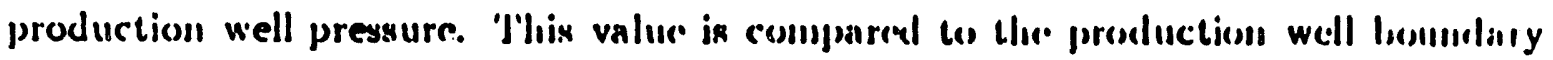
condition, and ileration continues until convergence is achieved, usually in five itra. tions. In the process, front lorations, temuperatures, pressures, and phase saturatiens are determined for encli of lluc zoncs. Siuce lice tcmperaturss and pressures are c:omn. puled, the compressibility and thermal expansion of the rock, oil, and water can br. considered. Oil and water production rates are calculated by malcrial haluncr:. In thr: two-dimensional model, a new empirical method is presented which determines the shape of the steam front, and an extension of an cxisting water flooding correlation is used to determine the volumetric sweep efficiency for the reservoir.

Many cases were run on both the SAM and a numerical model. The Computer Modelling Group's genrral purpose thormal simmlator ISC(O)M was uscrl for comrparisons. The SAM runs were several orders of magnitude faster than the thermal simulator, yet matched thermal simulator results accuralely in over 2,000 runs over a wide range of variables. The result is a computer program that can be run on a personal computer by a field engineer. The program is not intended to replace a thermal simulator. The simulator is more general and can handle meses lentailerl problemzs than the SAM. However, the SAM is iclcal for: (1) preliminary studies l,r. fore running a numerical model, (2) running nany cases for scnsitivity analysis and optimization, (3) screening prospective field projects, and (4) providing guidance. for operating decisions. 


\title{
SUPRI HEAVY OIL RESEARCH PROGRAM
}

THIRTEENTH ANNUAL REPORT

OCTOBER 1, 1988 - SEPTEMBER 30, 1989

TR-76

\author{
William E. Brigham, Principal Investigator \\ Henry J. Ramey, Jr., Co-Principal Investigator \\ Louis M. Castanier, Technical Manager
}

SUPRI's mission is to conduct research directed towards improved recovery of heavy oils. As most of the existing EOR techniques for heavy oils are thermal recovery methods, emphasis of SUPRI research is on in-situ combustion and steam injection. SUPRI effort is divided into five major projects:

\section{FLOW PROPERTIES STUDY}

To assess the effect of increased temperature and pressure on reservoir properties: This year's effort has focused on experimental determination of temperature effects on oil/water relative permeabilities in consolidated sandstones and on a computer modei allowing comparison of relative permeability data from displacement experiments with data obtained by centrifuge experiments. A report on the state of the art in computerized tomography applied to petroleum related experiments has been completed.

\section{IN-SITU COMBUSTION}

To study the parameters affecting in-situ combustion performance: A literature review of various ignition methods has been completed. An analytical study of multiphase multicomponent flow modeling with temperature changes is in progress. This work will be applied to oxygen enriched combustion. Metallic additives are studied in order to modify the reactions of combustion to increase or decrease the amount of fuel burned as needed. Tube runs allow quantitative measurements of the effect of water soluble metallic salts on the combustion of Huntington Beach crude oil.

\section{STEAM WITH ADDITIVES}

To improve sweep efficiency in steam injection: Transient flow of foams generated by surfactants in a sand pack are studied by Cat Scanning. This work should provide data allowing modeling of foam flow in porous media. Experiments aiming at the characterization of surfactants to be used as foaming additives in steam injection were performed. Study of the heat transfer parameters in laboratory experiments is emphazised. 


\section{RESERVOIR DEFINITION}

To improve reservoir knowledge before enhanced oil recovery projects: Single well tracer studies to estimate residual oil saturation have been performed. A description of flow through perforations has been completed and a study on the design and interpretation of thermal recovery well testing is in progress. Tracer breakthrough behavior is being studied at nonunity mobility ratio to help evaluate reservoir characteristics.

\section{FIELD SUPPORT SERVICES}

To help solving field related problems: A study on optimizing parallel computing by comparison of Newton and quasi-Newton methods is in progress. A semi-analytical model for steam drive is being derived, this model will allow simulation of dipping reservoirs. 


\title{
THEORETICAL DEVELOPMENT OF FLOW INTO A WELL THROUGH PERFORATIONS
}

\author{
SUPRI TR 77
}

By

G. Ahmed, R. N. Home and W . E. Brigham

May 1990

\begin{abstract}
A theoretical solution to flow into a well via perforations is synthesized using Green's functions. The solution is three dimensional and applies to steady-state single phase homogeneous flow. The complete solution for a cylindrical perforation involves double infinite oummation and triple integration and is difficult to compute. A useful approximation is made by treating the perforation as a line-sink; this reduces the solution to a double infinite summation and a single incegration.

The solution contains expressions of Bessel functions and their derivatives. The infinite summation is over the order and the argument of these functions. An array of eigenvalues are first computed from an implicit equation. These eigenvalues are then used for computation of a solution.

The solution involves five physical parameters: wellbore diameter, perforation diameter, perforation length, perforation density (vertical spacing) and phasing (angular spacing). These parameters influence the cost as well as the efficiency of a well completion. A sensitivity analysis can be done for an optimization of the completion design using this analytical solution.

Perforation length is the most important parameter and performance improves with increasing length. Initially, even a small increase in length gives a significant improvement. Perforation density is an important parameter, but beyond an optimum number of shots per foot there is little gain in productivity ratio. This result will lead to a saving of cost, since a higher shot density is generally used by industry. The phasing of perforations influences the performance. A phasing of $90^{\circ}$ in the same horizontal plane or along a spiral gives a significant advantage over $0^{0}$ phasing, and this improvement increases with an increase in perforation length.
\end{abstract}

Further work is needed to extend the solution for uniform potential but variable flow rate along the length of a perforation. 


\title{
EFFECT OF METALLIC ADDITIVES ON IN-SITU COMBUSTION
}

\section{OF HUNTINGTON BEACH CRUDE EXPERIMENTS}

\author{
SUPRI TR 78
}

By

C.J. Baena, L.M. Castanier and W.E. Brigham

June 1990

\begin{abstract}
The economic ard applicability of an in-situ combustion process for the recovery of crude oil are dictated to a large extent by the nature and the amount of fuel formed during the process. If the amounis of fuel deposited is insufficient, as in the case of light oil reservoirs, the combustion front vill not be self sustaining. If excessive fuel is deposited, as in the case of very heavy oil reservoirs, the air requirements will be excessive and the process may not be economically viable. Through kinetic studies on crude oil oxidation in porous media, metals have been shown, on a qualitative basis, to affect the nature and the amount of fuel formed. The aim of this work is to use combustion tube studies to determine on a quantitative basis, how the nature and the amount of fuel formed could be changed by the presence of metallic additives.

These experiments follow from the qualitative observations on the effect of metallic additives on the in-siru combustion of Huntington Beach crude oil made by De los Rios (1987) at SUPRI. He performed binetic studies on the oxidation of Huntington Beach crude in porous media and showed that the nature of the fuel formed changed when metallic addi. tives were present.

In this study, combustion tube runs were performed using the metallic additives: ferrous chloride $\left(\mathrm{FeCl}_{2} \cdot 4 \mathrm{H}_{2} \mathrm{O}\right)$, zinc chloride $\left(\mathrm{ZnCl}_{2}\right)$ and stannic chloride $\left(\mathrm{SnCl}_{4} \cdot 5 \mathrm{SH}_{2} \mathrm{O}\right)$. Soluble salts of these metals were selected from the results observed in De Los Rios' kinetic studies. Unconsolidated cores were prepared by mixing predetermined amounts of an aqueous solution of the metal salt, Huntington Beach crude oil, Ottawa sand and clay in order to achieve the desired fluid saturations. The mixture was then tamped into the combustion tube. Dry air combustion tube runs were performed keeping the conditions of saturation, air flux and irjection pressure approximately the same during each run.
\end{abstract}


The nature of the fuel formed and its impact on the combustion parameters were determined and compared with a control run - an experiment performed with no metallic additive. It was found that the presence of metallic additives increased the atomic hydrogen 10 carbon ratio of the fuel from 0.07 for the control nun to 0.13 in the presence of ferrous chloride, 0.61 with zine chloride and 0.79 with stannic chloride. The $\mathrm{H} / \mathrm{C}$ ratio of the fuel coupled with the extent to which the oxidation formed $\mathrm{CO}_{2}$ in preference to $\mathrm{CO}$ affected the following combustion parameters: velocitv of the combustion front, heat of combustion of the deposited fuel, air requirements at $100 \%$ combustion efficiency, the air/oil ratio and the oil recovery rates. As a result of the increased hydrogen content of fuel, the heat of combustion and the air requirements at $100 \%$ combustion efficiency increased as the H/C ratio increased. The metallic additives increased the burning front velocity and the oil recovery rate. However these were found to be affected by the oxygen utilization efficiency, the nature and the amount of fuel formed and the air flux. 


\title{
CHARACTERIZATION OF SURFACTANTS AS STEAMFLOOD ADDITIVES
}

\author{
SUPRI TR 79
}

By

\author{
F. M. Hamida, B. M. R. Demiral, L. M. Castanier and W. E. Brigham
}

June 1990

\begin{abstract}
Steamflood efficiency can be increased by adding surface active agents to steam such that foam can be generated, can preferentially reduce permeability to steam in previously swept zones, and can divert the steam to undepleted regions of the reservoir. Even though the detrimental effect of oil on foam formation has been observed since the mid 1960's, most of the laboratory testing of surfactants as steamflood additives was performed with no oil present. In this study, a linear model was used to compare and characterize eight surfactants as steamflood additives under typical California conditions of moderate temperature and pressure. The evaluation of foamability was based on pressure gradient changes and steam mobility reduction along the model. Two sets of experiments were made. In the first, no oil was present in the sandpack. In the second, West Newport crude oil was used at residual saturation afier steam flooding. All runs were performed under the same operating conditions!

Results from the first set of runs indicated that alpha olefin sulfonates generated the strongest foam. Flow resistance due to foam increased as the alkyl chain length increased. Enrichment in disulfonate content enhanced the propagation speed of an alpha olefin sulfonate but reduced its foam strength. Significant steam mobility reduction was achieved for all surfactar's tested. Relative permeability to steam was reduced to between 0.005 and 0.02 when no oil was present. Analysis of temperature and pressure profiles indicated the formation of a nitrogen foam ahead of a steam foam. This proves that nitrogen can help stabilize and maintain foam as steam condenses away from the injection port. In the presence of oil, no increase in pressure gradient was observed for any of the surfactants tested.
\end{abstract}




\title{
SUPRI HEAVY OIL RESEARCH PROGRAM \\ FOURTEENTH ANNUAL REPORT \\ OCTOBER 1, 1989 - SEPTEMBER 30, 1990
}

TR-80

\author{
Khalid Aziz, Principal Investigator \\ Henry J. Ramey Jr., Principal Investigator \\ Louis M. Castanier, Technical Manager
}

This page summarizes the progress made during the 1989-1990 fiscal year. The organization of this report in sections refers to the following projects:

\section{Project 1: Flow Properties}

A study of end effects in oil/water displacements is in progress. The experimental apparatus has been built and calibrated. One run has been made and it showed that inlet end effects may be important during imbibition. The work on the CT Scanner has focused on software implementation and development of new experiments on fractured media, drying and wetting fluids distribution and validation of other nondestructive measurements.

\section{Project 2: In-Situ Combustion}

Results of a study of metallic additives for in-situ combustion are presented. Tube runs and kinetics experiments have been performed on Huntington Beach and Hamaca crudes. The equipment was updated by replumbing all the lines, installing pressure relief valves and acid scrubbers ahead of the gas analyzers and improving gas and liquid analysis by addition of two chromatographs. Oil samples have been requested from se reral companies. A study of residual oil saturation after steam injection and how it relates to the fuel consumption has been initiated. Correlations of residual oil saturation with gravity will be attempted and verified experimentally. As a first step distillation data have been obtained and are now being analyzed.

\section{Project 3: Steam with Additives}

A model for transient foam flow is being developed. The results of the model will be compared with experimental data. Screening of surfactants in the presence of residual oil has continued. It appears that the injection procedure greatly affects the performance of the process. A new micromodel for foam observations is being built using computer technology. This micromodel will be used to study the effect of oil on the flow behavior of foams at the pore level. A three dimensional steam injection model allowing measurement of saturations by CT scan has been built. Preliminary runs with steam displacing water showed that the model can be operated as planned and that saturations in gas-liquid systems can be accurately measured. Foam runs are now in progress. 


\section{Project 4: Formation Evaluation}

A study of the evaluation of saturations following waterflooding has been completed. Work on the numerical simulation of well-to-well tracer tests has continued. The main problem in this project remains numerical dispersion for large cell Peclet numbers. More research is needed to solve this problem.

\section{Project 5: Field Support}

Although no specific section on this project appears in this report, SUPRI has continued communicating with industry via our Industrial Advisory Committee and to advise the Department of Energy on a variety of field projects. SUPRI personnel also attended SPE meetings and various other technical conferences. 


\title{
STEAM DISTILLATION EFFECT AND OIL QUALITY CHANGE DURING STEAM INJECTION
}

\author{
SUPRI TR 81
}

By

K. T. Lim, H. J. Ramey, Jr., and W. E. Brigham

June 1991

\begin{abstract}
Steam distillation is an important mechanism which reduces residual oil saturation during steam injection. It may be the main recovery mechanism in steamflooding of light oil reservoirs. As light components are distilled from the residual (initial) oil, the residuum becomes heavier. Mixing of the distilled components with the initial oil results in a lighter produced oil.

A general method has been developed to compute steam distillation yield and to quantify oil quality changes during steam injection. The quantitative results are specific because the California crude data bank was used. But general principles were followed and calculations were based on information extracted from the DOE crude oil assay data bank.

It was found that steam distillation data from the literature can be correlated with the steam distillation yield obtained from the DOE coude oil assays. The common basis for comparison was the equivalent normal boiling point.

Blending of distilled components with the initial oil results in API gravity changes similar to those observed in several laboratory and field operations.
\end{abstract}




\title{
TRANSIENT FOAM FLOW \\ IN POROUS MEDIA WITH CAT SCANNER
}

\author{
SUPRI TR 82
}

By

Dianbin Liu

W.E. Brigham

October 1991

\section{Abstract}

Transient behavior is likely to dominate over most of the duration of a foam injection field project. Due to the lack of data, little is presently known about transient foam flow behavior. Foam flow does not follow established models such as the Buckley-Leverett theory, and no general predictive model hes been derived. Therefore, both experimental data and a foam flow theory are needed.

In this work, foam was injected at a constant mass rate into one-dimensional andpacks of 1-in diameter and 24-in or 48-in length that had initially been saturated with distilled water. The system was placed in a CAT Scanner. Data, obtained at room temperature and low pressure at various times, include both the pressure and saturation distributions.

Pressure profiles showed that the pressure gradient is much greater behind the foam front than abead of it. Moreover, the pressure gradients keep changing as the foam advances in the sandpack. This behavior differs from Buckley-Leverett theory. The CT scan results demonstrated gas channeling near the front, but eventually the foam blocks all these channels and sweeps the entire cross cection after many pore volumes of injection. 
Three series of experiments were run: (1) eurfactant adeorption mearurements, (2) gas displacements of surfactant-laden solutions and (3) foam displacements. The first two series of experiments were made to provide the necessary parameters required to match the foam displacements. To this end, it was necessary to smooth the saturation history data, using a Langmuir-type formula.

A theory was proposed based on the principles of the fractional flow curve construction method. This foam theory treats the foam as composed of infinitesimal slugs of gas of varying viscosities. The foam front has the lowest viscosity and foam at the injection end has the highest. 


\section{A THREE-DIMENSIONAL LABORATORY STEAM \\ INJECTION MODEL ALLOWING IN SITU \\ SATURATION MEASUREMENTS}

SUPRI TR 83

By

Birol M.R. Demiral

Paul A. Pettit

Louis M. Castanier

William E. Brigham

June 1992

\section{Abstract}

The CT imaging technique together with temperature and preasure measurements were used to follow the steam propagation during steam and steam foam injection experiments in a three dimeusional laboratory steam injection model. During the design period, the advantages and disadvantages of different geometries were examined to find out which could best represent radis and gravity override flows and also fit the dimensions of the scanning field of the CT scanner. As a result of this analysis a 3D rectangular box with dimensions $20 \times 20 \times 7.5 \mathrm{~cm}$ was constructed. This box simulates one quarter of a five spot pattern. Aluminum, Teflon ${ }^{T M}$ and Fiberfrax ${ }^{T M}$ were chosen as supporting and insulating materials. Tefion ${ }^{T M}$ was placed between the porous medium and the aluminum shell so that the rate of heat transfer in the porous medium would be much faster than that in the aluminum during a steam injection run. During experiments, steam was injected continuously at a constant rate into the water saturated model and CT scans were taken at six different cross sections of the model. Pressure and temperature data were collected with time at three different levels in the model. CT pictures and three dimensional temperature distributions were compared and analyzed in terms of observed steam zone at each section. To do that, CT numbers within the scan section were used to determine the steam and water zones, and with the aid of $x$-ray pictures the position and propagation of the steam zone were determined. In addition, using the three dimensional temperature distribution 
measurements at the same times, steam displacement fronts could be drawn at the scan section locations. These pictures and drawings were used to compare the results obtained from classical ternperature-pressure monitoring and from CT scans.

During steam injection experiments the saturations obtained by CT matched well with the temperature data. That is, the steam override as observed by temperature data was also clearly seen on the CT pictures.

During the runs where foam was present, the saturation distributions obtained from CT pictures showed a piston like displacement. However, the temperature distributions were different depending on the type of steam foam process used. During the experiment which included non-condensible gas (nitrogen) injection, the temperature distributions, contrary to the saturation distributions, still indicated the presence of steam override, although the override was reduced by the foam. However, when there was no nitrogen the temperature distributions followed the saturation distributions. This may possibly indicate that the nitrogen foam ahead of steam foam caused the difference between temperature and saturation distributions. These results clearly show that the pressure/temperature data alone are not sufficient to study steam foam in the presence of non-condensible gas. 


\title{
STEAM FOAM STUDIES IN THE PRESENCE \\ OF RESIDUAL OIL
}

\author{
SUPRI TR 84
}

By

\author{
David Anthony Hutchinson \\ Birol Demiral \\ Louis M. Castanier
}

March 1992

\section{Abstract}

The lack of understanding regarding foam flow in porous media necessitates further research. This paper reports on going work at Stanford University ; jmed at increasing our understanding in the particular area of steam foams.

The behavior of steam foam is investigated with a one dimensional ( $\left.6^{\prime} \times 2.15^{n}\right)$ sandpack under residual oil conditions of approximately 12 percent. The strength of the in-situ generated foam, indicated by pressure drops, is significantly affected by injection procedure, slug size, and steam quality. The surfactant concentration effect is minor in the range studied.

In the presence of residual oil the simultaneous injection of steam and surfactant fails to generate foam in the model, even though the same procedure generates a strong foam in the absence of oil. Nevertheless when surfactant is injected as a slug ahead of the steam using a surfactant alternating gas (SAG) procedure, foam is generated. The suggested reason for the success of SAG is the increased phase mixing that results from steam continually having to reestablish a path through a slug of surfactant solution.

The minimum slug size required to generate foam by SAG is about 5 percent of the model's pore volume. Above this minimum, increases in slug size or changes in surfactant concentration have little effect in the range studied. The injected steam quality, however, does affect foam strength. Reproducible results show that foam strength improves as the injected steam quality increases.

Experimental results imply that a savings in the total mass of surfactant needed for a foam flood may be possible by a SAG procedure that utilizes a sufficiently large slug volume. That is, if the slug volume is above some minimum then a dilute concenliration of surfactant may give acceptable foam generation. The converse is not true however as a high concentration of surfactant in a small slug volume is ineffective. The results also indicate that the continual washing away and dilution of surfactant by low quality steam injection is detrimental. 


\title{
SUPRI HEAVY OIL RESEARCH PROGRAM \\ Fourteenth Annual Report \\ October 1, 1989-September 30, 1990
}

\section{SUPRI TR 85}

\author{
Khalid Axiz \\ Henry J. Ramey Jr. \\ Louis M. Castanier
}

This page summarizes the progress made during the 1989-1990 fiscal year. The organization of this report in sections refers to the following projects:

Project 1: Flow Properties

A swudy of end effects in oil/water displacements is in progress. The experimental apparatus has been built and calibrated. One run has been made and it showed that inlet end effects may be important during imbibition. The work on the CT Scanner has focused on software implementation and development of new experiments on fractured media, drying and wetting fluids distribution and validation of other nondestructive measurements.

\section{Project 2: In-Situ Combustion}

Results of a study of metallic additives for in-situ combustion are presented. Tube runs and kinetirs experiments have been performed on Hunington Beach and Hamaca crudes. The equipment was updated by replumbing all the lines, installing pressure relief valves and acid scrubbers ahead of the gas analyzers and improving gas and liquid analysis by addition of two chromatogtaphs. Oil samples have been requested from se reral companies. A study of residual oil saturation after steam injection and how it relates to the fuel consumption has been initiated. Correlations of residual oil saturation with gravity will be atrempted and verified experimentally. As a first step distillation data have been obtained and are nCw being analyzed.

Project 3: Steam with Additives

A model for transient foam tow is being developed. The results of the model will be compared with experimental data. Sereening of surfactants in the presence of residual oil has continued. It appears that the injection procedure greatly affects the performance of the process. A new mictomodel for foam observations is being built using computer technology. This micromodel will be used to study the effect of oil on the flow behavior of foams at the pore level. A three dimensional steam injection model allowing measurement of saturations by CT scan has been built. Preliminary runs with steam displacing water showed that the model can be operated as planned and that sanurations in gas-liquid systems can be accurately measured. Foam runs are now in progress.

\section{Project 4: Formation Evaluation}

A study of the evaluation of saturations following waterflooding has been completed. Work on the numerical simulation of well-to-well tracer tests has continued. The main problem in this project remains numerical dispersion for large cell Peclet numbers. More research is needed to solve this problem.

\section{Project 5: Field Support}

Although no specific saction on this project appears in this repor, SUPRI has continued communicating with industry via our Industrial Advisory Committee and to advise the Department of Energy on a variety of field projects. SUPRI personnel also attended SPE meetings and various other rechnical conferences. 


\title{
VISUALIZATION OF FOAM/OIL
}

\author{
IN A NEW, HIGH RESOLUTION, \\ SANDSTONE REPLICA MICROMODEL
}

\author{
SUPRI TR 86
}

By

John Wirt Hombrook

Paul Pettit

Louis M. Castanies

April 1992

\section{Abstract}

A new micromodel construction procedure has been developed as a tool to better understand and model pore level events in porous media. The construction procedure allows for the almost exact two-dimensional replication of any porons medinm of interest. For the case presented bere, a berea sandstone was chosen.

Starting with a thin cection of the porous medium of interest, a two-dimencional replica of the flow path is etched into a silicon wafer to a prescribed depth. Bonding the etched pattern to a fiat glass plate isolates the flow path and allows the pore level flow events to be studied.

The high resolution micromodels constructed with the new procedure were used to study the effects of oil on the displacement characteristics of foam in a porous medium of intermediate wettability. A crude oil was injected into the micromodel, partially filling it. The oil was then produced under two different displacement schemes. First, a slug of surfactant was used. Second, foam generated in situ, far from the oil bank, was used to displace the oil.

Qualitative observations indicate significant differences at the interface between the oil and the displacing phase. When alug surfactant injection is used, the oil appears to wet the surface. The oil displacement process is efficient due to a large fractional production of oil from the large pcres before the surfactant breaks through. When in-situ foam is the displacing phase, the foam is observed to break near the oil interface. The liquid phase in the foam becomes the wetting phase. It is observed to reside in the small pores and to coat most of the grain surfaces. Displacement of oil under this injection scheme is inefficient due to transfer of the surfactant along grain edges and subsequent early breakthrough of the surfactant. 


\section{IN.SITU COMBUSTION \\ WITH METALLIC ADDITIVES}

SUPRI TR 87

By

Richard Joseph Holt

June 1992

\section{Abstract}

In-situ combustion is the most energy efficient of the thermal oil recovery methods. In this process, a portion of a reservoir's oil is burned in-situ as fuel to drive the recovery process. In light oil reservoirs, too little fuel may be deposited, making sustained combustion difficult. In heavy oil reservoirs, too much fuel may be deposited leading to high air injection requirements and unfavorable economics. This study has been designed to attack these problems. Water soluble metallic additives are investigated as agents to modify fuel deposition and combustion performance.

In previous papers (Shalleross 1989, De los Rios et al, 1988), results were reported from kinetics experiments run on Huntington Beach (California) and Hamaca (Venezuela) crude oils. In these experiments, mixtures of sand, crude oil, and aqueous metallic salts were oxidized. While the presence of copper, nickel and cadmium had little or no effect; iron and tin increased oxidation rates and oxygen consumption.

This report describes seven combustion tube runs using two crude oils and two metallic additives. The oils are $12^{\circ}$ and $34^{\circ} \mathrm{API}$, both from Cymric (California). The metallic additives tested are iron nitrate $\left(\mathrm{Fe}\left(\mathrm{NO}_{3}\right)_{3} 9 \mathrm{H}_{2} \mathrm{O}\right)$ and zinc nitrate $\left(\mathrm{Zn}\left(\mathrm{NO}_{3}\right)_{2} 6 \mathrm{H}_{2} \mathrm{O}\right)$. In previous studies, Baena et al (1990) and Castanier et al (1992), have presented a total of eight combustion tube runs with the metallic additives iron chloride $\left(\mathrm{FeCl}_{2} 4 \mathrm{H}_{2} \mathrm{O}\right)$, zinc chloride $\left(\mathrm{ZnCl}_{2}\right)$, and tin chloride $\left(\mathrm{SnCl}_{4} 5 \mathrm{H}_{2} \mathrm{O}\right)$ using Huntington Beach (California) and Hamaca (Venezuela) oils. 
Iron and tin additives improved the combustion efficiency in all cases. Fluctuations in the produced gas compositions were observed in all conteol runs, but nearly disappeared with the iron and tin additives. The combustion front velocities were also increased by iron and tin. Changes were also observed in the apparent hydrogen to carbon $(\mathrm{H} / \mathrm{C})$ ratio of the fuel, heat of combustion, air requirements, and amount of fuel deposited. Iron and tin caused increases in fuel concentration while causing a decrease in air requirement. The increase in fuel concentration varied between the oils, however, tin and iron were consistently more effective than zinc.

A particularly interesting result occurred with the Cymric light oil. In the control runs, a sustained combustion front was not achieved, while in the iron additive runs, stable, sustained combustion was achieved.

Iron and tin salts are suitable additives to increase fuel deposition when that is needed. Additives suitable for use as a fuel reducing agent have not yet bera found. 


\title{
CHARACTERIZATION OF SURFACTANTS \\ IN THE PRESENCE OF OIL FOR STEAM \\ FOAM APPLICATION
}

\author{
SUPRI TR 88
}

By

Abdul-Razzaq

Louis M. Castanier

\section{Abstract}

The steam foam process has been applied in the oil fields since the late 1970s. The mechanism of the process, however, is not known fully; particularly the detrimental effects of oil on foam, while known, are still unexplained. This hinders field application as the behavior of surfactants cannot be predicted under field conditions. Understanding the mechanisms of foam generation, stability, and mobility of foam to improve the development of field level projects has been the focus of the attention of many workers of the oil industry. Extensive laboratory studies have been carried out, mostly without oil but some with oil. This study falls in the later category.

A one dimensional sandpack ( $6 \mathrm{ft} X 2.15 \mathrm{in}$ ) model is used to investigate the behavior of four anionic sulfonate surfactants of varying chemical structure with steam. The study is performed with an crude oil at residual oil saturation of about 12 percent of the pore volume. The observed pressure drops across the various sections of the pack are used to study the behavior of the surfactant.

The tested surfactants vary in chain length, aromatic structure and number of ionic charges. A linear toluene sulfonate produced the highest strength foam in presence of the oil at residual saturations, as compared to the alpha olefin sulfonates. This is in contrast to the behavior of the surfactants in the absence of oil, where the alpha olefin sulfonates perform better. The reason for this change in behavior is the relative propagation rate of the foams produced by the surfactants. This conclusion is based on the observation that increase in propagation rate decreases the detrimental effect of oil; while the propagation rate is of little significance without oil.

The disulfonate performed better in the presence of oil. The improvement in the performance is embedded in the propagation rate of these surfactants as the rate of propagation in this case is also high. But the true mechanism of improvement in the strength of the foam instead of deterioration needs further study. 


\title{
ULTRASONIC RATE MEASUREMENT \\ OF MULTIPHASE FLOW
}

\author{
SUPRI TR 89
}

By

David A. Dannert

Roland N. Home

September 1992

\section{Abstract}

One of the most important tools in production logging and well testing is the downhole flowmeter. Unfortunately, existing tools are inaccurate outside of an idealized single phase flow regime. Spinner tools are inaccurate at extremely high or low flow rates and when the flow rate is variable. Radioactive tracer tools have similar inaccuracies and are extremely sensitive to the flow regime. Both tools completely fail in the presence of multiphase flow, whether gas/oil, gas/water or fluid/solid. (Bennett et al., 1991, Hill and Oolman, 1982, Hill, 1990 and McKinley, 1982)

Downhole flowmetering is important for locating producing zones and thief zones and monitoring production and injection rates. The effects of stimulation can also be determined. (Leach et al., 1974) 
This goal of this project is the investigation of accurate downhole flowmetering techniques for all single phase flow regimes and multiphase flows. The measurement method investigated in this report is the use of ultrasound. There are two ways to use ultrasound for fluid velocity measurement. The first method, examined in Chapter 2, is the contrapropagation, or transit-time, method which compares travel times with and against fluid flow. Chapter 3 details the second method which measures the Doppler frequency shift of a reflected sound wave in the moving fluid.

Ultrasonic fluid flow measurement was first proposed in Rütten's German Patent in 1928 (issued in 1931), using the transit-time method, for single phase liquid pipe flow. Commercial transit-time flowmeters have been available since the early 80's (Lynnworth, 1989) and one such was purchased and tested for this research. The results are found in Chapter 4. A natural 


\section{MULTIVARIATE OPTIMIZATION OF PRODUCTION SYSTEMS - \\ THE TIME DIMENSION}

SUPRI TR 90

By

Niranjan Ravindran

Roland N. Horne

June 1992

\section{Abstract}

Triditional analysis of oil and gas production systems treats individual nodes one at a time. This only calculates a feasible solution which is not necessarily optimal. Multivariate optimization is able to determine the most profitable configuration, including all variables simultaneously. The optimization can also find the optimal recovery over a period of time, rather than just at a single instant as in traditional methods..This report describes the development of multivariate optimization for situations in which the decision variables may change as a function of time. For example, instead of estimating a tubing size which is optimal over the life of the project, this approach determines a series of optimal tubing sizes which may change from year to year. Examples show that under an optimal strategy, tubing size can be changed only infrequently while still increasing profitability of a project. The methods used in this work considered the special requirements of objectives which are not smooth functions of their decision variables. The physical problems considered included artificial lift production systems. 


\section{SUPRI-A Publications Since 1989}

1. Falade, G.K. and Brigham, W.E.: "Analysis of Radial Transport of Reactive Tracer in Porous Media," SPE No. 16033, SPE Reservoir Engineering pp. 85-90 (February 1989).

2. Shallcross, D.C., De los Rios, C.F., Castanier, L.M. and Brigham, W.E.: "Modifying InSitu Combustion Performance by the Use of Water-Soluble Additives," SPE No. 19485, paper presented SPE Asia-Pacific Conference; also SPE Reservoir Engineering (August 1991).

3. Mossotti, V.G. and L.M. Castanier: "The Measurement of Water Transport in Salem Limestone by X-ray Computer Aided Tomography," Proc. IAEG International Symposium on the Engineering Geology of Ancient Works, Vol. 4, Athens (1989).

4. Mossotti, V.G. and L.M. Castanier: "Water Transport in Limestone by X-ray CAT Scanning," Proc. of ASCE Symposium on Structure of Materials, San Francisco (1989).

5. Shallcross, D.C., W.E. Brigham, and L.M. Castanier: "Characterization of Surfactants as Steamflood Additives," 3rd International Symposium on Heavy Crudes, Maricaibo (February 20-22, 1989).

6. Shallcross. D.C.: "Devices and Methods for In-situ Combustion Ignition," SUPRI TR-89 (1989).

7. Castanier, L.M., "Steam with Additives, Field Projects of the Eighties," Jour. of Pet. Science and Tech. 2 (April 1989) 192-206.

8. Gajdica, R.J., W.E. Brigham, and K. Aziz, "A Semianalytical Thermal Model for Linear Steam Drive," S'DE 20198, SPE/DOE Seventh Symposium on Enhanced Oil Recovery, Tulsa, OK (April 22-25, 1989).

9. Shallcross, D.C., De los Rios, C.F., Castanier, L.M. and Brigham, W.E.: "Modifying InSitu Combustion Performance by the Use of Water-Soluble Additives," SPE No. 19485, paper presented at the SPE Asia-Pacific Conference, Sydney, Australia (September 13-15, 1989).

10. Wingard, J.C. and Orr, F.M.: "An Analytical Solution for Steam/Oil/Water Displacements," SPE No. 19667, paper presented at the SPE Annual Technical Meeting, San Antonio (October 8-11, 1989).

11. Shallcross, D.C.: "Ignition Devices and Methods for In-Situ Combustion," paper presented at the 3rd International Symposium on Heavy Crudes, Maracaibo (February 20-22, 1989).

12. Brigham, W.E. and M.M. Kamal, "Authors' Reply to Discussions of "Pulse-Testing Response for Unequal Pulse and Shut-in Periods," Rebuttal, SPE 19365, SPE Formation Evaluation, p. 487 (1989). 
13. Brigham, W.E. and D.O. Ogbe, "A Correlation for Interference Testing with Wellbore Storage and Skin Effects," SPE 13253, SPE Formation Evaluation 4, No. 3, pp. 392-396 (1989).

14. Correa, A.C., K.K. Pande, H.J. Ramey, Jr. and W.E. Brigham, "Computation and Interpretation of Miscible Displacement Performance in Heterogeneous Porous Media," SPE Reservoir Engineering (February 1990) 69-78.

15. Castanier, L.M. and P.A. Pettit, "X-Ray Scanning in Petroleum Engineering, Engineering Laboratory Research," SPE 20087, paper presented at the SPE California Regional Meeting (April 4-6, 1990).

16. Hamida, F., D.C. Shallcross, B. Demiral, L.M. Castanier, and W.E. Brigham, "Further Characterization of Surfactants as Steamflood Additives, SPE 20065, paper presented at the SPE California Regional Meeting, Ventura (April 4-6, 1990).

17. Liu, D., L.M. Castanier, and W.E. Brigham, "Analysis of Transient Flow in 1-D Porous Media with CT," SPE 20071, paper presented at the SPE California Regional Meeting, Ventura (April 4-6, 1990).

18. Castanier, L.M. and W.E. Brigham, "An Evaluation of Field Projects of Steam with Additives," SPE Reservoir Engineering, pp. 62-69 (February 1991).

19. Johns, R.A., J. Steude, L.M. Castanier, and P.V. Roberts, "Nondestructive Measurements of Fracture Aperture in Crystaline Rocks Using X-Ray Tomography," J.R. 6 "B" (May 1991).

20. Riley, M.F. and W.E. Brigham, "Determining Barrier Curve," SPE 22656, unsolicited paper (June 1991).

21. Hornbrook, J., L.M. Castanier, and W.E. Brigham, "Visualization of Foam/Oil Interaction in a High Resolution Sandstone Micromodel," paper to be presented at the SPE Annual Meeting, Dallas, (October 1991).

22. Demiral, B.D.M., L.M. Castanier, and W.E. Brigham, "Experiments on Steam Flow Behavior," IEA Conference, Bath, England (October 1991).

23. Demiral, B.D.M., L.M. Castanier, and W.E. Brigham, "CT Imaging of Steam and Steam Foam Experiments," paper presented at the SPE Annual Technical Conference and Exhibition, Dallas (October 6-9, 1991).

24. Castanier, L.M., C.J. Baena, R.J. Holt and W.E. Brigham," "In-situ Combustion with Metallic Additives," SPE 23708, paper presented at the Second Latin American Petroleum Engineering Conference, II LAPEC, Caracas (March 8-11, 1992).

25. Hutchinson, D.A., B.D.M. Demiral, and L.M. Castanier, "Steam Foam Studies in the Presence of Residual Oil," SPE 23709, paper presented at the Second Latin American Petroleum Engineering Conference, II LAPEC, Caracas (March 8-11, 1992). 
26. Lim, K.T., H.J. Ramey, Jr. and W.E. Brigham," Steam Distillation and Oil Quality Change During Thermal Oil Recovery," SPE 23718, paper presented at the Second Latin American Petroleum Engineering Conference, II LAPEC, Caracas (March 8-11, 1992).

27. Liu, Dianbin, L.M. Castanier and W.E. Brigham, "Displacement by Foam in Porous Media," SPE 24664, paper presented at the 67th Annual Technical Conference and Exhibition, Washington, D.C. (October 4-7, 1992).

28. Castanier, L.M., H.J. Ramey, Jr. and W.E. Brigham, "Thermal Recovery Research at Stanford University," paper presented St. Petersburg 1992 International Symposium and Exhibition, Leningrad (October 12-16, 1992). 

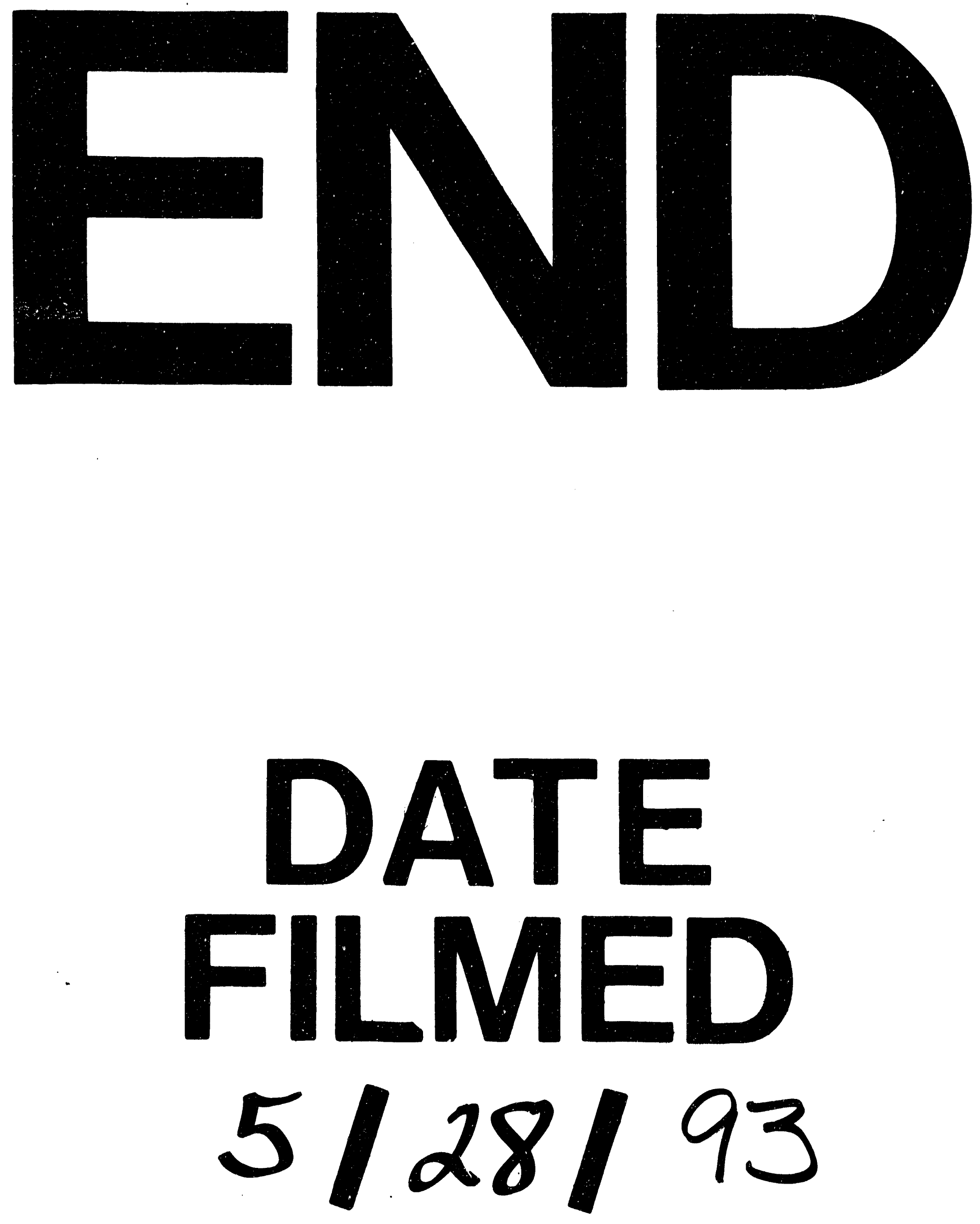
